\title{
FORMATION OF SKILLS OF ORAL FOREIGN LANGUAGE SPEECH IN YOUNGER SCHOOL CHILDREN
}

\author{
Aigul Niyazova1, Asel Kurmakh² \\ ${ }^{1}$ Eurasian National University named after L.N. Gumilyov, Kazakhstan, Nur-Sultan \\ ${ }^{2}$ Eurasian National University named after L.N. Gumilyov, Kazakhstan, Nur-Sultan
}

ORCID ID: 0000-0003-1440-800X

\begin{abstract}
ANNOTATION
The article examines the main difficulties in the formation of the skills of oral foreign language speech in primary school children, also exercises, the use of which contributes not only to a more effective assimilation of educational material but also to the formation of students' communication skills.
\end{abstract}

\section{INTRODUCTION}

It is a well-known fact that when communicating in a foreign language foreign language, the learner has difficulty understanding speech by ear. At the moment the role of oral communication is quite significant because in the process of communication the learner acts both as a listener and as a speaker. The role of the speaker. The problem of teaching oral communication has been investigated by a variety of specialists over the years. Psychological aspects of the problem under study were developed by P.Y. Galperin, L.S. Vygotsky, N.I. Zhinkin, D.B. Elkonin, who showed an important feature of the situation in which the learner is learning English Language learner. [Vygotsky L.S., 1982].

The attention of foreign language learners is simultaneously distributed to several objects: the selection of the necessary language means, the identification of the content of the utterance, the establishment of the logical sequence of the utterance, as well as its implementation during the speech. The teacher needs to help students not only organize their own thoughts, but also clarify when solving the task, actualize educational motivation, with the help of which the communicative process will be implemented, given the fact that English lessons at the initial stage of education are specific. Their specificity lies not only in the age characteristics of students, but also in the tasks facing this age, in its content, as well as in the psychological fact that students of this period begin learning.

The basis of the beginning of training plays an important role in the future. All students come to school with a different, often insufficiently developed level of ability to master speech activity. All educational activities will be extremely difficult if the student does not have developed visual memory, if he is not able to retain several words in his memory, cannot imitate, and does not distinguish sounds. Of course, in the learning process, the abilities of students develop, but teachers need to purposefully engage in this type of activity, starting from the first lessons. For example, for students, you should prepare several phrases consisting of two words and ask the students to repeat each phrase after it by ear at once. In the next lesson, you need to do this work, but using phrases with a gradually increasing number of words. After a while, students will be fluent in speech units. Hence, it should concluded that students will have developed the ability to imitate, auditory memory, and the quality of speech will improve.

It should be noted that pronunciation is also one of the main tasks when teaching to speak a foreign language. Pronunciation skills mean clear pronunciation of individual sounds and sound combinations in speech, correct logical stress in a phrase, correct stress in words, intonation and pauses. Before children begin to imitate sounds, they need to listen carefully and understand how each sound is to be pronounced. That is why the teacher needs to make sure that the students are silent at first. In this case, the whole class will hear the teacher and "feel" the place of sound articulation. First, the sounds heard are pronounced by strong students, then the students are weaker, and only then the whole choir enters. This work will contribute to the development of students' phonemic hearing and the formation of pronunciation skills. [Passov E.I., Kuzovleva N.E., 2009]. 
Speaking is an extremely multifaceted and complex phenomenon. With the help of this type of speech activity, oral verbal communication is carried out. It has varying complexity, since it includes both expressions of a simple exclamation, and independent detailed statements. The transition from a word and a phrase to a whole utterance is associated with varying degrees of participation of thinking and memory. It should noted that speaking has certain features that serve as a guide in learning, since they indicate the conditions that need to be created for the development of speaking, and are also criteria for assessing learning outcomes. [Solovova E.N., 2002].

In grade 2, when the formation of monologue speech skills is just beginning, there is no strict differentiation into the main types of monologue, since the emphasis is on expanding the use of linguistic material, its accumulation and combination within the framework of various speech situations.

In the 3rd grade, the skills of monologue speech are actively being formed: students learn to talk about themselves and their family, about their hobbies and pets; they describe the appearance of people, the appearance and basic habits of animals, talk about the seasons and their characteristic fun in the framework of the studied lexical and grammatical material.

In grade 4, the formation of monologue speech skills continues: students learn to give basic information about their hometown and sights. As practice shows, speech situations that are closest to real life increase the effectiveness of the lesson and activate both speech activity and the motivation of students.

If unfavorable conditions are created for the speaking process in the lesson, then students may have difficulties. Let's list the main ones:

1. Students begin to feel embarrassed to speak English, afraid to make mistakes and criticize themselves from classmates and the teacher.

2. Students do not have enough information on a certain issue in their native language and, therefore, they will not be able to express their own thoughts in English.

3. Students do not have enough language and speech means to solve the problem.

4. When one student speaks, the rest are silent, which means that there is a danger of their exclusion from educational communication, ineffective use of lesson time.

5. Students often switch to using their native language in pair and group forms of work.

Learning to speak is always conditioned by communication situations. Any task containing the goal of simulating a monologue or dialogical utterance can be completed subject to the following conditions:

- Students understand the essence of the task;

- Speech tasks are based on an interesting plot typical for children of this age, which is a natural stimulus to speak;

- Learners have the information necessary to answer;

- The video sequence and the formulation of the task provide the necessary level of content, speech and language support;

- Learners possess speech patterns necessary for solving a given communicative task.

The experience of working in the elementary grades shows that when difficulties arise, it is necessary to use training exercises to develop skills and speaking skills, which serve to develop grammatical and lexical skills. Traditionally, exercises for substitution, repetition, transformation and connection of several speech patterns used for this purpose. [Maslyko E.A., Babinskaya P.K., 2015] Recommended at these stages of the lessons include guessing games, games with information gap elements (Information gap activities) and others that can turn a routine task into an exciting competition, for example: a mini-dialogue that students can play out on their own using the support on the cards:

1. Dialogue "In the store". Selected from each of the two teams, one vendor. The product can be drawn on cards. Team №1 buyers buy from Team №2 seller and vice versa.

A. Tell the seller what you want to buy: A please.

B. Say that you have such a product and give it to the buyer: Oh, I have Here you are!

C. Thank the seller: Thank you. Show everyone that you have bought. Look! I have a 
Then the task should be complicated. While one buys, others interfere: they ask questions - "I would like to ask you ...", "And how much does it cost?" The winner is the one who is better able to clearly and loudly explain in English what he needs, despite the interference. The presented type of activity indicates that students build independent statements based on a sample.

2. Working with unfinished sentences (sentence-stem sheet). Students are encouraged to supplement the sentences with information that matches their own life experiences, for example:

1. The first thing I do when I visit my grandmother is ... (give her cake)

2. Just before I go to sleep, I ... (wash my face)

3. Just before friends arrive, I ... (cook / clean my house)

4. Everyone knows that... (Cats can jump / etc.)

Then the teacher needs to distribute the students into groups of three. He asks students $\mathrm{A}$ and $B$ in each group to guess what student $C$ is doing in the situations presented with the help of unfinished sentences. Students have to guess until they get closer to the option that corresponds to the truth. Then, in a similar way, students change roles and try to guess what the other students are doing in the proposed situations. Such a rather simple technique projects a mobile and interested exchange of opinions between them. [Passov E.I., Kuzovleva N.E., 2009].

3. Story pyramid.

The presented task, in addition to knowing the content of the read, requires knowledge of vocabulary on a certain topic and the ability to think rationally.

The first line: the main character. (The main character);

The second line: two words for describing the main character.

(Description of the main character in a nutshell);

The third line: three words for describing the setting;

The fourth line: four words for stating the main problem;

The fifth line: five words for describing one main event (description of the main event in five words);

The sixth line: six words for describing the next event;

The seventh line: seven words or describing the third event (description of the third event in seven words);

The eighth line: eight words for stating the solution of the problem (the solution to a problem in eight words).

The use of the training exercises presented above contributes not only to a more effective assimilation of educational material, but also to the formation of students' communication skills, and bright figurative supports can help to establish appropriate associations.

In order for speech to be sufficiently formed, the speaker's intention to participate in communication is necessary [Barannik D.Kh., 2014]. With the help of games, it is necessary to create a situation in the educational process of a modern school at the initial stage of education. It should also be note that the initial stage is important in teaching English speaking, because it is at this stage that fundamental communication skills formed, which helps to achieve the necessary results.

\section{REFERENCES}

Vygotsky L.S. (1982) Collected Works in 6 volumes. Volume 2. Problems of general psychology.

Passov E.I., Kuzovleva N.E. (2009) Foreign language lesson

Solovova E.N. (2002) Methodology for teaching foreign languages. Basic course of lectures. - M.: Education

Maslyko E.A., Babinskaya P.K. (2015) Handbook of a foreign language teacher. - Minsk: Higher school

Barannik D.Kh. (2014) Oral monologue speech (features of the linguistic structure and functionalstyle typology of monologue speech): author. diss. Dr. ped. sciences 